\title{
Diabetic Ketoacidosis - An Ephimeral Review
}

\author{
Kasu Vyshnavi*, Nagireddy Pravalika and Nikhil Kumar Vanjari \\ Department of Clinical Pharmacy, Vaageswari College of Pharmacy, India
}

Submission: June 06, 2019; Published: June 21, 2019

*Corresponding author: Kasu Vyshnavi, Pharm D, Department of Clinical Pharmacy, Vaageswari College of Pharmacy, Karimnagar, Telangana, 505001, India

\begin{abstract}
Diabetes mellitus could be a cluster of metabolic diseases defined by chronic hyperglycemia succeeding from defects in hypoglycemic agent (insulin) secretion, hypoglycemic agent action, or both. Recent epidemiological studies indicate that hospitalizations for diabetic ketoacidosis in the U.S. are increasing. Together the decreased amount insulin concentrations, as well as increased concentrations of counter-regulatory hormones like catecholamines, cortisol, glucagon, and growth hormone, leads to an elevated glucose level [hyperglycemia] and ketosis[ketonebodies] in diabetic ketoacidosis. Assess clinical evaluation to determine the diagnosis and confirm its cause. carefully look for evidence of infection. This article reviews clinical aspects and pathophysiology of diabetic ketoacidosis and its management in emergency conditions.
\end{abstract}

Keywords: Diabetic ketoacidosis; Hyperglycemia; Ketones; Insulin; Ketonuria; Catecholamines; Cortisol; Glucagon; Growth hormone; Ketonebodies; Infection; Macromolecule; Saccharide; Fat; Macromolecule; Protein; Metabolism

\section{Introduction}

Diabetes mellitus could be a cluster of metabolic diseases defined by chronic hyperglycemia succeeding from defects in hypoglycemic agent (insulin) secretion, hypoglycemic agent action, or both. The abnormalities in macromolecule (saccharide), fat, and macromolecule (protein) metabolism that is present in polygenic disorders due to inadequate action of insulin secretion on target tissues. If ketones were found in blood or body waste(urine), treatment imperative as a result of acidosis will evolve rapidly $[1,2]$.

\section{Diabetes is classified into the subsequent general cat- egories:}

a) Type-1 Diabetes is caused due to autoimmune beta-cell destruction, sometimes resulting in absolute insulin deficiency.

b) Type-2 diabetes is caused due to a progressive loss of beta-cell insulin secretion often developing insulin resistance.

c) Gestational diabetes mellitus (GDM) is diagnosed within the second or trimester of pregnancy.

d) Specific varieties of Diabetes due to different causes, e.g., monogenic diabetes syndromes.

e) such as diabetes in infants and maturity-onset of diabetes in the young (MODY), diseases of the exocrine duct gland (pancreas)such as cystic fibrosis, and drug or chemical-induced Diabetes mellitus like glucocorticoid use and in the treatment of HIV/AIDS, or post-organ transplantation. [3].
Complication of new-onset IDDM is diabetic ketoacidosis and may be defined as a metabolic unbalance characterized by the triad hyperglycemia $(250 \mathrm{mg} / \mathrm{dl})$, acidosis (arterial pH 7.3 and/or bicarbonate $15 \mathrm{mEq} / \mathrm{l}$ ), and ketonuria. [4,5]. Newly diagnosed diabetics were reported in $20-40 \%$ of patients with diabetic ketoacidosis [6], and when unrecognized. This can lead to impairment of consciousness and even death [7].

The most common precipitating factor in the development of diabetic ketoacidosis is an infection. Other co-factors include discontinuation of or inappropriate insulin therapy, pancreatitis, myocardial infarction, cerebrovascular accident, and drugs. In addition, new-onset type 1 diabetes or discontinuation of insulin in established type 1 diabetes commonly leads to the development of diabetic ketoacidosis. In young patients with type 1 diabetes, eating disorders may complicate psychological problems which is a contributing factor in $20 \%$ of recurrent ketoacidosis. Factors that contribute to insulin depletion in younger patients include fear of weight gain with improved metabolic control, fear of hypoglycemia and stress of chronic disease [8].

\section{Epidemiology}

Recent epidemiological studies indicate that hospitalizations for diabetic ketoacidosis in the U.S. are increasing. In the decade from 1996 to 2006, there was a 35\% increase in the number of cases, with a total of 136,510 cases with a primary diagnosis of diabetic ketoacidosis in 2006 a rate of increase perhaps more rapid than the overall increase in the diagnosis of diabetes [9]. Most patients with diabetic ketoacidosis were between the ages 


\section{Current Research in Diabetes \& Obesity Journal}

of 18 and 44 years [56\%] and 45 and 65 years [24\%], with only $18 \%$ of patients 20 years of age. Two-thirds of diabetic ketoacidosis patients were considered to have type 1 diabetes and $34 \%$ to have type 2 diabetes; $50 \%$ were female, and $45 \%$ were nonwhite. Diabetic ketoacidosis is the most common cause of death in children and adolescents with type 1 diabetes and accounts for half of all deaths in diabetic patients younger than 24 years of age $[10,11]$.

In adult subjects with diabetic ketoacidosis, the overall mortality is $1 \%$ [9], however, a mortality rate of $5 \%$ has been reported in the elderly and in patients with concomitant life-threatening illnesses $[12,13]$. Death in these conditions is rarely due to the metabolic complications of hyperglycemia or ketoacidosis but relates to the underlying precipitating illness [14]. Mortality attributed to hyperosmolar hyperglycemic state is considerably higher than that attributed to diabetic ketoacidosis, with recent mortality rates of $5-20 \%[15,16]$. The prognosis of both conditions is substantially worsened at the extremes of age in the presence of coma, hypotension, and severe comorbidities $[8,9,13,17]$.

\section{Pathogenesis}

Together the decreased amount insulin concentrations, as well as increased concentrations of counter-regulatory hormones like catecholamines, cortisol, glucagon, and growth hormone, leads to an elevated glucose level [hyperglycemia] and ketosis[ketonebodies] in diabetic ketoacidosis. Hyperglycemia occurs as a result of increased gluconeogenesis and reduced glucose utilization by peripheral tissues [8,17-22]. This is magnified by transient insulin resistance due to the hormone imbalance itself as well as the elevated free fatty acid concentrations [8]. The combination of both insulin deficiency and increased concentrations counterregulatory hormones in diabetic ketoacidosis also leads to the release of free fatty acids into the blood circulation from adipose tissue [lipolysis] and to unrestrained hepatic fatty acid oxidation in the liver to ketone bodies i.e. hydroxybutyrate and acetoacetate [10], which resulting in ketonemia and metabolic acidosis.

The other precipitating factors include insulin deficiency as the initial primary event in gradual cell failure, its ineffectiveness in a patient with the established disease, or its relative reduced potency when insulin action is antagonized by physiological factors such as sepsis and increased counterregulatory hormone. These hormonal variations enhance glucose production from glycogenolysis and gluconeogenesis and moreover limiting glucose utilization by the cells, resulting in increased glucose levels [11 mmol/l [200 mg/dl]], osmotic diuresis, loss of electrolyte, dehydration, decreased glomerular filtration and hyperosmolarity. The clinical symptoms include polyuria, polydipsia, dehydration, deep sighing respirations to reduce pCO2 and buffer acidosis, and gradual obtundation leading to coma. The severity of diabetic ketoacidosis is described by the degree of acidosis: mild ie, $\mathrm{pH}$ 7.2-7.3; moderate, ie, $\mathrm{pH}$ 7.1-7.2 and severe ie, $\mathrm{pH}<7.1$ [23].

\section{Management of Diabetic Ketoacidosis}

Emergency assessment: Assess a clinical evaluation study to confirm the diagnosis and detect its cause. In recurrent diabetic ketoacidosis look for the evidence of infection. Weigh the patient if the body surface area is used for fluid therapy calculations, measure height and length to assess the surface area. Assessment of the clinical severity of dehydration is necessary but accurate clinical assessment of dehydration may be difficult in diabetic ketoacidosis, at least in part due to the hyperosmolar state and polyuria caused by osmotic diuresis. Some findings that may be helpful include: 5\%: reduced skin turgor, dry mucous membranes, tachycardia, 10\% weak or impalpable peripheral pulses, hypotension, shock, oliguria. Assess level of consciousness [Glasgow coma scale] [24,25] Collect a blood sample for laboratory measurement of serum or plasma glucose; electrolytes including bicarbonate or total carbon dioxide [TCO2]];,urea nitrogen; creatinine, determination of $\mathrm{pH}$ in venous; hemoglobin and hematocrit levels, complete blood count, calcium, phosphorus, and magnesium concentrations, HbA1c levels, and blood_ hydroxybutyrate [--OHB] concentration is also necessary [26]. [An increased white blood cell count in response to stress is characteristic of diabetic ketoacidosis and is not indicative of infection. Perform a urinalysis for determination of ketones. If there are any manifestations of infection is found, obtain appropriate specimens for culture test i.e., blood, urine, and throat. If laboratory measurement of serum potassium is deferred, perform an electrocardiogram for a baseline evaluation of potassium levels $[27,28]$.

\section{Supportive Measures}

In the unconscious or severely immobilized patients, secure the airway and clear the stomach by continuous nasogastric suction to prevent pulmonary aspiration. For a comfortable and safe repetitive blood sampling, a peripheral intravenous catheter may be placed. A continuous electrocardiographic monitoring should be performed to assess $\mathrm{T}$ waves to detect any evidence of hyper or hypokalemia and to monitor for arrhythmias [29,30]. In case of severe circulatory impairment or shock, oxygen is recommended. After obtaining appropriate cultures of body fluids give antibiotics in febrile patients. Usually, Catheterization of the bladder is not necessary, but if the patient is unconscious or unable to clear on demand in case of, infants and very ill young children, the bladder should be catheterized.

Monitoring of Central venous pressure may be rarely required to guide fluid management in the critically ill, or neurologically compromised patient. Children with diabetic ketoacidosis are frequently associated with thrombosis and should be resorted to only when absolutely necessary. Children with severe diabetic ketoacidosis with longer duration of symptoms, reduced circulation, or depressed level of consciousness or those 


\section{Current Research in Diabetes \& Obesity Journal}

who are at increased risk for cerebral oedema [e.g.5 years of age, low pCO2, high urea nitrogen] should be considered for urgent treatment in an intensive care unit or in a unit that has equivalent resources and supervision, such as a children's ward specializing in diabetes care $[29,30]$.

\section{Fluid Therapy}

For expansion of intravascular, interstitial and intracellular volume which are gradually reduced in hyperglycemic patients the initial fluid therapy is indicated [31] and to restore the renal perfusion. Isotonic saline $[0.9 \% \mathrm{NaCl}]$ is infused at a rate of $15-$ $20 \mathrm{ml} / \mathrm{kg}$ body weight should be given in the absence of cardiac comprise patients. The choice for fluid replacement depends on many factors like hemodynamics, the state of hydration, serum electrolyte levels, and urinary output. Normally, $0.45 \% \mathrm{NaCl}$ infused at a rate of $250-500 \mathrm{ml} / \mathrm{hr}$ if the serum sodium is normal or elevated; and $0.9 \% \mathrm{NaCl}$ at a similar rate is appropriate if corrected serum sodium is low. Hemodynamic monitoring like improvement in blood pressure, measurement of fluid input or output, laboratory values, and clinical examinations are necessary to determine the successful fluid therapy. When the plasma glucose level reaches $200 \mathrm{mg} / \mathrm{dl}$, then add 5\% dextrose to replacement fluids in order to allow continued insulin administration until ketonemia is controlled while at the same time avoiding hypoglycemia.

\section{Insulin}

Diabetic ketoacidosis is due to decreased effective circulating insulin which is associated with an elevated counterregulatory hormones like glucagon, catecholamines, growth hormone, cortisol. Even though rehydration alone causes some amount of decreased blood glucose level concentration [32,33], but insulin is still essential to normalize blood glucose and suppress lipolysis and ketogenesis [34]. After the patient has received initial volume expansion; i.e., 1-2 $\mathrm{h}$ after starting fluid replacement therapy then start insulin infusion [35]. The dose is 0.1unit/ $\mathrm{kg} / \mathrm{hr}$ [50 units regular insulin diluted in $50 \mathrm{ml}$ normal saline; 1 unit $/ 1 \mathrm{ml}$ ] [36].The dose of insulin should remain at $0.1 \mathrm{unit} / \mathrm{kg} /$ $\mathrm{hr}$ at least until the resolution of diabetic ketoacidosis $[\mathrm{pH} 7.30$, bicarbonate $15 \mathrm{mmol} / \mathrm{l}$, which invariably takes longer than the normalization of blood glucose concentrations [37].

If the patient manifests any marked sensitivity to insulin in case of some young children with diabetic ketoacidosis or patients with the hyperglycemic hyperosmolar syndrome, the dose may be decreased to 0.05 units/ $\mathrm{kg} / \mathrm{hr}$, or less, provided that metabolic acidosis continues to resolve. If any biochemical parameters of diabetic ketoacidosis like $\mathrm{pH}$, anion gap still do not improve, reassess the patient and review insulin therapy, and determine or consider other possible causes of altered response to insulin e.g., infection, errors in insulin preparation. If no obvious cause is found, increase the insulin infusion rate and adjust the rate of glucose infusion as needed to maintain a glucose concentration of _17 mmol/l $[300 \mathrm{mg} / \mathrm{dl}]$. When intravenous administration could not be possible hourly/2-hourly in some conditions so subcutaneous or intramuscular administration of a short or rapid-acting insulin analog like insulin lispro or insulin as part is a safe and effective alternative to intravenous regular insulin infusion [38-42].

\section{Potassium}

Children with diabetic ketoacidosis suffer total-body potassium deficits of the order of $3-6 \mathrm{mmol} / \mathrm{kg}[35,36]$. Loss of potassium largely occurs from the intracellular pool. Intracellular potassium is reduced because of transcellular shifts of this ion caused by hypertonicity. Increased plasma osmolality results in osmotic water transport from cells to the ECF, thereby concentrating cellular potassium. Potassium is drawn out of cells as a result of increased potassium gradient. Glycogenolysis and proteolysis which are secondary to insulin deficiency may also cause potassium efflux from cells. But acidosis may play a minor role in the distribution of potassium to the ECF. As a result of vomiting, urinary ketoanion excretion which requires excretion of cations, particularly sodium and potassium, and osmotic diuresis potassium gets gradually depleted from the body. Volume depletion may also lead to secondary hyperaldosteronism, which promotes urinary potassium excretion.

Thus, total-body depletion of potassium occurs, but at presentation serum potassium levels may be normal, increased, or decreased [43]. Administration of insulin and the correction of acidosis drives potassium back into the cells, decreasing serum levels [44]. The serum potassium concentration may be reduced suddenly, predisposing the patient to cardiac arrhythmias. Start potassium replacement immediately after initial volume expansion and before starting insulin therapy if the patient is hypokalemic. The initial potassium concentration in the infusion should be $40 \mathrm{mmol} / \mathrm{l}$; subsequent replacement therapy of potassium should be based on serum potassium level measurements. Potassium administration should be continued throughout the period of intravenous fluid therapy is continued. Potassium phosphate may be also used in combination with potassium chloride or acetate [e.g., $20 \mathrm{mmol} / \mathrm{l}$ potassium chloride and $20 \mathrm{mmol} / \mathrm{l}$ potassium phosphate or $20 \mathrm{mmol} / \mathrm{l}$ potassium phosphate and $20 \mathrm{mmol} / \mathrm{l}$ potassium acetate] develops, administration of phosphate should be stopped. An alternative like Potassium phosphate salts may also be safely used or it is used in combination potassium chloride or acetate provided that careful monitoring is performed to avoid hypocalcemia $[45,46]$.

\section{Acidosis}

Fluid and insulin replacement can reverse the severe acidosis. Insulin can stop further ketoacid production and allows ketoacids to be metabolized, which generates bicarbonate. Treating hypovolemia improves tissue perfusion and renal function, thereby increasing the excretion of organic acids. Controlled trials have shown no clinical benefit from bicarbonate administration [47-50], and there are well recognized adverse effects of bicarbonate therapy, including paradoxical CNS acidosis [51,52] and hypokalemia from rapid correction of acidosis [51,53,54]. 
Reducing the $\mathrm{NaCl}$ concentration of the fluids can result in increased osmolality [51]. In few patients, there might be benefit from cautious alkali therapy like in patients with severe acidemia whose arterial $\mathrm{pH}$ is 6.9 , in whom decreased cardiac contractility and peripheral vasodilatation can further impair tissue perfusion and patients with life-threatening hyperkalemia [55]. Bicarbonate administration is not recommended for resuscitation unless the acidosis is profound and likely to during resuscitation. If bicarbonate is considered necessary, cautiously administer 1-2 mmol/kg over $60 \mathrm{~min}$. diversely affect the action of epinephrine during resuscitation. If bicarbonate is considered necessary, cautiously administer $1-2 \mathrm{mmol} / \mathrm{kg}$ over $60 \mathrm{~min}$ [24].

\section{Conclusion}

Diabetic ketoacidosis is a medical emergency that is handled effectively with an organized approach. It is a severe complication of diabetes and should be immediately diagnosed by a proper approach to reduce further complications.

\section{References}

1. (2009) Diagnosis and Classification of Diabetes Mellitus. Diabetes Care 33(1): S62-S67.

2. (1999) Definition, Diagnosis and Classification of Diabetes Mellitus and its Complications. Part 1: Diagnosis and Classification of Diabetes Mellitus. WHO/NCD/NCS/99.2. Geneva.

3. (2014) American Diabetes Association. Diagnosis and classification of diabetes mellitus. Diabetes Care 37(Suppl 1): S81-S90.

4. Kitabchi AE, Fisher JN, Beth Murphy M, Rumbak MJ (1994) Diabetic ketoacidosis and the hyperglycemic, hyperosmolar nonketotic state. In: Kahn CR, Weir GC, (Eds.), Diabetes Mellitus. (13 ${ }^{\text {th }}$ edn.), Philadelphia, Lea \& Febiger, pp. 738-770.

5. Drash AL (1996) Management of the child with diabetes mellitus. In: Lifshitz F, (Eds.), Paediatric Endocrinology: A Clinical Guide. ( $3^{\text {rd }}$ edn.), New York, Marcel Dekker, USA, pp. 617-629.

6. Santiago JV, White NH, Pontious SL (1992) Diabetes in childhood and adolescence. In: Alberti KGMM, Defronzo RA, Keen H, Zimmet P (Eds.), International Textbook of Diabetes Mellitus Chichester, Wiley, UK, pp. 1025-1057.

7. Rosenbloom AL (1990) Intracerebral crises during treatment of diabetic ketoacidosis. Diabete Care 13(1): 22-33.

8. Kitabchi AE, Umpierrez GE, Miles JM, Fisher JN (2009) Hyperglycemic crises in adult patients with diabetes. Diabetes care 32 (7): 1335-1343.

9. (2009) National Center for Health Statistics. National hospital discharge and ambulatory surgery data.

10. Wolfsdorf J, Glaser N, Sperling MA (2006) Diabetic ketoacidosis in infants, children, and adolescents: a consensus statement from the American Diabetes Association. Diabetes Care 29(5): 1150-2259.

11. White NH (2000) Diabetic ketoacidosis in children. Endocrinol Metab Clin North Am 29: 657-682.

12. Graves EJ, Gillium BS (1995) The National Center for Health Statistics. Detailed diagnoses and procedures: National Hospital Discharge Survey. Vital Health Stat 1 1997(130): 1146.

13. Malone ML, Dennis V, Goodwin JS (1992) Characteristics of diabetic ketoacidosis in older versus younger adults. J Am Geriatr Soc 40(11): 1100-1104.
14. Umpierrez GE, Kelly JP, Navarrete JE, Casals MM, Kitabchi AE (1997) Hyperglycemic crises in urban blacks. Arch Intern Med 157(6): 669675.

15. Ennis ED, Stahl EJB, Kreisberg RA (1994) The hyperosmolar hyperglycemic syndrome. Diabetes Rev 2: 115-126.

16. Lorber D (1995) Nonketotic hypertonicity in diabetes mellitus. Med Clin North Am 79(1): 39-52.

17. Kitabchi AE, Fisher JN, Murphy MB, Rumbak MJ (1994) Diabetic ketoacidosis and the hyperglycemic hyperosmolar nonketotic state. In: Kahn CR, Weir GC, (Eds.), Joslin's Diabetes Mellitus. (13 ${ }^{\text {th }}$ edn.), Philadelphia, Lea \& Febiger, pp. 738-770.

18. DeFronzo RA, Matzuda M, Barret E (1994) Diabetic ketoacidosis: a combined metabolic nephrologic approach to therapy. Diabetes 2(2): 209-238.

19. Luzi L, Barrett EJ, Groop LC, Ferrannini E, DeFronzo RA (1988) Metabolic effects of low dose insulin therapy on glucose metabolism in diabetic ketoacidosis. Diabetes 37(11): 1470-1477.

20. van de Werve G, Jeanrenaud B (1987) Liver glycogen metabolism: an overview. Diabetes Metab Rev 3: 47-78.

21. Felig P, Sherwin RS, Soman V, Wahren J, Hendler R, et al. (1979) Hormonal interactions in the regulation of blood glucose. Recent Prog Horm Res 35: 501-532.

22. Barrett EJ, DeFronzo RA, Bevilacqua S, Ferrammi E (1982) Insulin resistance in diabetic ketoacidosis. Diabetes 31(10): 923-928.

23. Teasdale G, Jennett B (1974) Assessment of coma and impaired consciousness: a practical scale. Lancet 2(7872): 81- 84.

24. Reilly PL, Simpson DA, Sprod R, Thomas L (1988) Assessing the conscious level in infants and young children: a paediatric version of the Glasgow Coma Scale. Childs Nerv Syst 4(1): 30-33.

25. Wiggam MI, O'Kane MJ, Harper R, Atkinson AB, Hadden DR, et al. (1997) Treatment of diabetic ketoacidosis using normalization of blood 3-hydroxybutyrate concentrations as the endpoint of emergency management: a randomized controlled study. Diabetes Care 20(9): 1347-1352.

26. Malone JI, Brodsky SJ (1980) The value of electrocardiogram monitoring in diabetic ketoacidosis. Diabetes Care 3(4): 543-547.

27. Soler NG, Bennett MA, Fitzgerald MG, Malins JM (1974) Electrocardiogram as a guide to potassium replacement in diabetic ketoacidosis. Diabetes 23(7): 610-615.

28. Monroe KW, King W, Atchison JA (1997) Use of PRISM scores in triage of pediatric patients with diabetic ketoacidosis. Am J Manag Care 3(2): 253-258.

29. Dunger DB, Sperling MA, Acerini CL, Bohn DJ, Daneman D, et al. (2004) ESPE, LWPES: ESPE/LWPES consensus statement on diabetic ketoacidosis in children and adolescents [Review]. Arch Dis Child 89(2): 188-194.

30. McDonnell CM, Pedreira CC, Vadamalayan B, Cameron FJ, Werther GA (2005) Diabetic ketoacidosis, hyperosmolarity and hypernatremia: are high-carbohydrate drinks worsening initial presentation? Pediatr Diabetes 6(2): 90-94.

31. Hillman K (1987) Fluid resuscitation in diabetic emergencies: a reappraisal. Intensive Care Med 13(1): 4-8.

32. Waldhausl W, Kleinberger G, Korn A, Dudczak R, Bratusch-Marrain P, et al. (1979) Severe hyperglycemia: effects of rehydration on endocrine derangements and blood glucose concentration. Diabetes 28(6): 577584. 
33. Owen OE, Licht JH, Sapir DG (1981) Renal function and effects of partial rehydration during diabetic ketoacidosis. Diabetes 30(6): 510-518.

34. Luzi L, Barrett EJ, Groop LC, Ferrannini E, DeFronzo RA (1988) Metabolic effects of low-dose insulin therapy on glucose metabolism in diabetic ketoacidosis. Diabetes 37(11): 1470-1477.

35. Edge J, Jakes R, Roy Y, Widmer B, Ford- Adams ME (2005) The UK prospective study of cerebral oedema complicating diabetic ketoacidosis. Arch Dis Child 90(Suppl 11): A2-A3.

36. Schade DS, Eaton RP (1977) Dose response to insulin in man: differential effects on glucose and ketone body regulation. J Clin Endocrinol Metab 44(6): 1038-1053.

37. Soler NG, FitzGerald MG, Wright AD, Malins JM (1975) Comparative study of different insulin regimens in management of diabetic ketoacidosis. Lancet 2(7947): 1221-1224.

38. Fisher JN, Shahshahani MN, Kitabchi AE (1977) Diabetic ketoacidosis: low-dose insulin therapy by various routes. N Engl J Med 297(5): 238241.

39. Sacks HS, Shahshahani M, Kitabchi AE, Fisher JN, Young RT (1979) Similar responsiveness of diabetic ketoacidosis to low dose insulin by intramuscular injection and albumin-free infusion. Ann Intern Med 90(1): 36-42.

40. Umpierrez GE, Latif K, Stoever J, Cuervo R, Park L, et al. (2004) Efficacy of subcutaneous insulin lispro versus continuous intravenous regular insulin for the treatment of patients with diabetic ketoacidosis. Am J Med 117(5): 291-296.

41. Umpierrez GE, Cuervo R, Karabell A, Latif K, Freire AX, et al. (2004) Treatment of diabetic ketoacidosis with subcutaneous insulin aspart. Diabetes Care 27(8): 1873-1878.

42. Della Manna T, Steinmetz L, Campos PR, Farhat SC, Schvartsman C, et al. (2005) Subcutaneous use of a fast-acting insulin analog: an alternative treatment for pediatric patients with diabetic ketoacidosis. Diabetes Care 28(8): 1856-1861.

43. Adrogue HJ, Lederer ED, Suki WN, Eknoyan G (1986) Determinants of plasma potassium levels in diabetic ketoacidosis. Medicine [Baltimore] 65(3): 163-172.

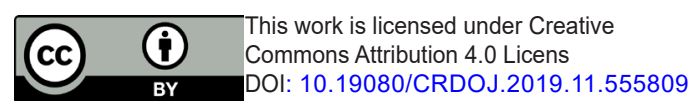

44. DeFronzo RA, Felig P, Ferrannini E, Wahren J (1980) Effect of graded doses of insulin on splanchnic and peripheral potassium metabolism in man. Am J Physiol 238(5): E421-E427.

45. Zipf WB, Bacon GE, Spencer ML, Kelch RP, Hopwood NJ, et al. (1979) Hypocalcemia, hypomagnesemia, and transient hypoparathyroidism during therapy with potassium phosphate in diabetic ketoacidosis. Diabetes Care 2(3): 265-268.

46. Winter RJ, Harris CJ, Phillips LS, Green OC (1979) Diabetic ketoacidosis: induction of hypocalcemia and hypomagnesemia by phosphate therapy. Am J Med 67(5): 897-900.

47. Hale PJ, Crase J, Nattrass M (1984) Metabolic effects of bicarbonate in the treatment of diabetic ketoacidosis. Br Med J [Clin Res Ed] 289(6451): 1035-1038.

48. Morris LR, Murphy MB, Kitabchi AE (1986) Bicarbonate therapy in severe diabetic ketoacidosis. Ann Intern Med 105(6): 836-840.

49. Okuda Y, Adrogue HJ, Field JB, Nohara H, Yamashita K (1996) Counterproductive effects of sodium bicarbonate in diabetic ketoacidosis. J Clin Endocrinol Metab 81(1): 314-320.

50. Green SM, Rothrock SG, Ho JD, Gallant RD, Borger R, et al. (1998) Failure of adjunctive bicarbonate to improve outcome in severe pediatric diabetic ketoacidosis. Ann Emerg Med 31(1): 41-48.

51. Assal JP, Aoki TT, Manzano FM, Kozak GP (1974) Metabolic effects of sodium bicarbonate in management of diabetic ketoacidosis. Diabetes 23(5): 405-411.

52. Ohman JL Jr, Marliss EB, Aoki TT, Munichoodappa CS, Khanna VV, et al. (1971) The cerebrospinal fluid in diabetic ketoacidosis. N Engl J Med 284(6): 283-290

53. Soler NG, Bennett MA, Dixon K, FitzGerald MG, Malins JM (1972) Potassium balance during treatment of diabetic ketoacidosis with special reference to the use of bicarbonate. Lancet 2(7779): 665-667.

54. Lever E, Jaspan JB (1983) Sodium bicarbonate therapy in severe diabetic ketoacidosis. Am J Med 75(2): 263-268.

55. Narins RG, Cohen JJ (1987) Bicarbonate therapy for organic acidosis: the case for its continued use. Ann Intern Med 106(4): 615-618.

\begin{tabular}{l} 
Your next submission with Juniper Publishers \\
will reach you the below assets \\
- Quality Editorial service \\
- Swift Peer Review \\
- Reprints availability \\
- E-prints Service \\
- Manuscript Podcast for convenient understanding \\
- Global attainment for your research \\
- Manuscript accessibility in different formats \\
( Pdf, E-pub, Full Text, Audio) \\
- Unceasing customer service \\
Track the below URL for one-step submission \\
https://juniperpublishers.com/online-submission.php \\
\hline
\end{tabular}

